\title{
Zonas do Perfil Conceitual de Calor que Emergem na Fala de Professores de Química
}

\author{
Zones of the Conceptual Profile of Heat that emerge in Chemistry \\ teachers' speeches
}

Antônio Inácio Diniz Júnior, João Roberto Ratis Tenório da Silva e Edenia Maria Ribeiro do Amaral

\begin{abstract}
Resumo: O perfil conceitual vem sendo apresentado na literatura como um modelo explicativo para o processo de ensino e aprendizagem de ciências. Pesquisas sobre perfis conceituais apontam para a importância de o estudante tomar consciência dos diferentes modos de pensar sobre um conceito específico de forma a compreender e situar ideias científicas introduzidas na escola. Consideramos importante que também o professor tenha consciência dessa pluralidade de sentidos que um conceito a ser ensinado pode adquirir. Neste trabalho, tivemos o objetivo de identificar zonas do perfil conceitual de calor que emergiram na fala de dois professores, em aulas de química, e analisar as percepções que estes podem apresentar sobre suas concepções. As aulas foram registradas em vídeo, trechos de fala foram transcritos e analisados. Também foram realizadas entrevistas com os professores. Os resultados mostram a emergência de quatro zonas do perfil conceitual - realista, substancialista, empirista e racionalista - nas falas dos dois professores, e sugerem que eles não têm percepção das suas concepções. Esses resultados apontam para a necessidade de reflexão por parte dos professores sobre as suas concepções, de forma que possam adotar estratégias apropriadas para mediar a discussão com os estudantes, guiando-os para a compreensão dos diversos significados que um único conceito pode adquirir em situações e contextos diversos, incluindo o contexto científico.
\end{abstract}

Palavras-chave: Perfil conceitual. Calor. Concepções e percepção de professores.

\begin{abstract}
Conceptual profile has been presented in Science Education literature as an explicative model for science teaching and learning. Researches on conceptual profiles point out the importance for students to be aware on different modes of thinking a specific concept, in order to understanding and situating scientific ideas, when they are introduced at school instruction. We consider also relevant that teachers must be aware on the diversity of meanings implicated on a specific concept to be taught. In this work, we aimed to identify zones for conceptual profile of heat that emerged from two teachers' speech in chemistry lessons, and to analyze perceptions that teachers could express on their own conceptions. Lessons were video recorded and pieces of teachers' speech were transcribed and analyzed. Also teachers were interviewed. Results show the emergency of four zones of the conceptual profile of heat - realistic, substancialist, empiric and rationalist - and suggest that teachers do not express perception on their own conceptions. These results point out that teachers might think about their own conceptions looking for appropriate strategies to guide students in the classroom discussion, taking into account different meanings that a scientific concept can acquire in specific contexts or situations, including scientific context.
\end{abstract}

Keywords: Conceptual profile. Heat. Conceptions and perception of teachers.

Antônio Inácio Diniz Júnior (junyordiniz07@hotmail.com), licenciado em Química (UFRPE), é mestrando do Programa de Pós-graduação em Ensino das Ciências (UFRPE). Recife, PE - BR. João Roberto Ratis Tenório da Silva (joaoratistenorio@ gmail.com), licenciado em Química (UFRPE), mestre em Ensino das Ciências (UFRPE), doutorando em Psicologia Cognitiva (UFPE), é professor assistente da Universidade Federal Rural de Pernambuco. Recife, PE - BR. Edenia Maria Ribeiro do Amaral (edsamaral@uol.com.br), graduada em Engenharia Química (UFPE), mestre em Ciências e Tecnologias Energéticas Nucleares (UFPE), doutora em Educação (UFMG), pós-doutorado no Centre for Studies in Science and Mathematics Education, University of Leeds, é professora associada da Universidade Federal Rural de Pernambuco. Recife, PE - BR.

Recebido em 13/10/2014, aceito em 02/02/2015 
Neste artigo, utilizamos o perfil conceitual de calor (Amaral; Mortimer, 2001) com o objetivo de identificar diferentes zonas que emergem na fala de professores em aulas de química, quando estes fazem a mediação no processo de construção de significados para esse conceito. Mais especificamente, buscamos identificar diferentes modos de pensar que o professor pode expressar quando apresenta os conceitos em sala de aula, utilizando a teoria do perfil conceitual (Mortimer, 1995; Mortimer; El-Hani, 2014). Além disso, analisamos o quanto o professor tem percepção do perfil de concepções que apresenta.

Em qualquer sala de aula, pode ser constatada uma heterogeneidade de modos de pensar e falar sobre os conteúdos estudados. Perfis conceituais podem ser compreendidos como modelos usados por indivíduos para significar as suas experiências a partir de diferentes modos de ver e conceituar o mundo (Mortimer et al., 2014), que são representados por zonas distintas. Na literatura, encontramos trabalhos que propõem perfis conceituais e identificam zonas para diferentes conceitos científicos a partir da análise de interações discursivas em sala de aula, evidenciando a fala de estudantes. Contudo, existem poucas pesquisas que aplicam essa teoria para a análise da fala produzida pelo professor.

As zonas de um perfil conceitual são constituídas considerando compromissos epistemológicos e ontológicos distintos na compreensão de um conceito e representam uma visão particular de mundo que pode ser associada a um contexto específico (Mortimer, 2000). Nesse sentido, ao trabalhar com a identificação de zonas de um perfil conceitual na fala do professor, estamos evidenciando a emergência de visões epistemológicas implicadas na abordagem do conhecimento científico em sala de aula, o que pode ter rebatimento nas estratégias de ensino adotadas. Ao identificar zonas do perfil conceitual que emergem na fala do professor, esperamos contribuir para que estes reconheçam e reflitam sobre as suas concepções, as implicações epistemológicas e pedagógicas que elas encerram e sobre suas práticas docentes, buscando adotar inovações para o ensino.

\section{Discussão epistemológica na formação e na ação docente}

O papel do professor tem sido reconhecido como essencial para a organização e construção de conhecimentos, sendo a profissão docente considerada como peça fundamental na formação de sujeitos que constituem o desenvolvimento de povos e nações. Segundo Chaves, Coutinho e Mortimer (2009), o trabalho do professor deve ser compreendido como uma atividade social, por meio da qual ele pode promover interações entre diferentes indivíduos, ao mesmo tempo em que constrói sentidos e realiza inclusões no espaço da sala de aula. Nesse sentido, acreditamos que essa função mediadora do professor deve ser valorizada, apesar das grandes transformações sociais, em que as tecnologias ganham espaço em todos os segmentos da vida dos sujeitos, incluindo o contexto de formação na escola.
Em geral, os professores enfrentam dificuldades para exercer plenamente a função docente, considerando que, em muitos casos, não há infraestrutura favorável para o trabalho no ambiente escolar, são sentidas lacunas oriundas da formação inicial, e os programas de formação continuada são escassos e pouco articulados com a prática na escola. Com relação a lacunas verificadas na formação inicial, destacamos que, em muitos casos, o professor tem pouco ou nenhum conhecimento sobre aspectos epistemológicos relacionados aos conceitos discutidos em sala de aula. De acordo com Moreira et al. (2007) e Scheid et al. (2009 apud Junqueira; Maximiano, 2011), ao longo dos últimos anos, pesquisas em ensino de ciências apontam para a necessidade de incluir uma reflexão crítica sobre as concepções epistemológicas na formação inicial de professores.

Segundo Cachapuz et al. (2011), um entendimento de questões epistemológicas pode ajudar os professores a melhor incorporarem diferentes concepções implicadas na construção dos conhecimentos, adotando uma abordagem didático-pedagógica mais ampla para os conteúdos a serem ensinados. Desse modo, os autores sugerem que os professores devem refletir sobre suas concepções epistemológicas para que assim consigam engrandecer as estratégias de ensino adotadas em sala de aula. Inúmeras pesquisas em ensino de química apontam para estratégias inovadoras que visam superar uma visão tradicionalista do ensino e que buscam levar os professores a tomarem consciência sobre aspectos epistemológicos, didáticos e pedagógicos implicados nestas (Junqueira; Maximiano, 2011). Segundo Gil-Pérez et al. (2001 apud Cachapuz et al., 2011, p. 71):

[...] resultados referem que as concepções de ciência que os professores possuem têm implicações no modo como ensinam e, se assim é, torna-se necessário criar espaços e tempos em que o professor deve contatar com as principais concepções de ciência, refletir nelas, discuti-las, confrontá-las, aprofundando suas próprias concepções e daí retirando indicações, orientações e ensinamentos quanto às estratégias, métodos e procedimentos a adotar no seu trabalho docente.

Destacamos que quando os autores apontam para uma reflexão sobre concepções de ciência, ressaltam a importância de que os professores compreendam as suas visões sobre o conhecimento científico e como o abordam no ambiente escolar para que, dessa forma, possam (re)orientar a sua ação docente. $\mathrm{Na}$ discussão em sala de aula, podem surgir conflitos que não resultam simplesmente da interação entre sujeito e objeto do conhecimento, mas, sobretudo, da emergência de novas exigências epistemológicas introduzidas pelo discurso da ciência por meio da ação docente. Nas aulas de ciências, frequentemente os conflitos emergem como resultado de uma longa e paciente intervenção do professor (Aguiar Jr.; Mortimer, 2005). 
Junqueira e Maximiano (2011) destacam a importância de uma formação epistemológica dos professores, capacitando-os para a dinâmica da sala de aula, na qual devem prevalecer novos olhares acerca do conhecimento científico e suas múltiplas relações na construção de saberes, e buscando valorizar as ideias prévias dos estudantes. Cachapuz et al. (2011) corroboram com essa ideia quando afirmam que as conexões entre epistemologia e educação em ciência são essenciais aos professores no sentido de fundamentar as opções pedagógicas destes de forma que elas estejam intrinsecamente relacionadas com o contexto sociocultural, o que se reflete ontológica e epistemologicamente na construção racional e produção social da ciência com incidências na educação científica.

Neste trabalho, consideramos que uma aproximação entre aspectos epistemológicos e ensino de conceitos científicos pode ser feita a partir do uso de perfis conceituais em sala de aula. Amaral e Mortimer (2004) afirmam que o conhecimento de zonas do perfil conceitual pode contribuir para o professor ampliar o repertório de estratégias usadas na discussão de um conceito em foco, incluindo aí a abordagem de aspectos históricos, epistemológicos e contextuais. Dessa forma, buscamos identificar zonas do perfil conceitual de calor nas falas produzidas por dois professores em aulas de química e avaliamos se eles apresentam uma percepção da emergência de diferentes zonas no seu próprio discurso.

\section{O perfil conceitual e a sala de aula}

Mortimer (1995) propôs a noção de perfil conceitual como uma forma de estruturação de diferentes modos de pensar um conceito, incluindo as concepções informais apresentadas pelos estudantes. Segundo Mortimer (1997), um princípio básico do perfil conceitual é que as pessoas têm distintas maneiras de ver e representar o mundo, e que diferentes modos de pensar sobre um conceito podem encontrar sentido em contextos particulares e serem compartilhadas por diferentes sujeitos. De acordo com o autor, concepções prévias dos sujeitos são resistentes a mudanças, uma vez que algumas dessas ideias encontram sentido no senso comum e em outros contextos.

Por meio da noção do perfil conceitual, é possível estabelecermos relações entre diferentes modos como os indivíduos compreendem e aplicam seus conhecimentos em diferentes contextos. A elaboração de um perfil conceitual prevê a estruturação de ideias em diversas zonas que representam compromissos epistemológicos e ontológicos distintos. Cada zona do perfil corresponde a uma forma de pensar e falar sobre a realidade, que convive com outras formas diferentes num mesmo indivíduo. Cada zona de um perfil conceitual é uma maneira de os indivíduos perceberem o meio que os cercam, verificando que em cada contexto teremos diferentes formas de ver e explicar as coisas (Mortimer, 1997).

Em estudos posteriores, a noção de perfil conceitual foi ampliada teoricamente, alinhada com a perspectiva sociocultural, a partir da qual a aprendizagem em ciências é compreendida como a aprendizagem da linguagem social da ciência escolar (Mortimer; Scott, 2002). Entre outros, pressupostos teóricos do construtivismo contextual (Cobern, 1996), da aprendizagem (Vygostky, 1971; 1981; 1987) e da linguagem (Bakhtin, 1981; 1987) foram articulados à noção de perfil conceitual, constituindo um modelo teórico para análise de modos de pensar, modos de falar e do processo de conceituação em situações de ensino e aprendizagem de ciências (Mortimer et al., 2014). Segundo Mortimer e Scott (2002), as recorrentes pesquisas sobre perfis conceituais integraram um arcabouço teórico que pode contribuir para a aprendizagem de ciências por meio de interações discursivas em sala de aula que incluam diferentes modos de pensar um conceito a ser ensinado. De acordo com os autores, esse arcabouço entrelaça a aprendizagem escolar à construção de significados que podem ser expressos pelos sujeitos a partir da maneira com que expõem suas ideias e anseios.

Consideramos que o perfil conceitual pode se constituir em um forte subsídio para o trabalho na sala de aula, uma vez que possibilita a professores e estudantes a construção de uma visão holística sobre diversas formas de compreensão de conceitos, aplicadas a diferentes contextos. Silva e Amaral (2013) destacam o fato de que o indivíduo pode apresentar uma forma de pensar não científica em seu dia a dia e ter a consciência de que tal concepção não é aceita em um contexto científico, compreendendo assim que determinadas situações e fenômenos podem ser explicados de maneira diferente pela ciência. O perfil conceitual pode contribuir para que os estudantes percebam e organizem a heterogeneidade das suas ideias, evidenciadas por meio das zonas do perfil conceitual, promovendo uma aprendizagem mais ampla e significativa (Silva, 2011). Dessa forma, o perfil conceitual pode ser considerado como um importante instrumento para o planejamento do ensino pelo professor (Amaral; Mortimer, 2001; 2004). Para isso, faz-se necessário que os professores tenham conhecimento das zonas do perfil conceitual para um conceito de interesse, o que poderá contribuir para ampliar a discussão em sala de aula. É também desejável que reconheçam zonas do perfil conceitual que podem emergir nessa discussão.

Na sala de aula, podemos verificar que diferentes modos de pensar sobre um único conceito podem emergir nas falas dos estudantes. Se os professores tiverem conhecimento desses modos de pensar, estruturados em perfis conceituais, poderá ser mais fácil adotar estratégias apropriadas para mediar e acompanhar a discussão com os estudantes, guiando-os para a compreensão dos diversos significados que um único conceito pode adquirir em situações e contextos diversos, incluindo e evidenciando o contexto científico. De acordo com Mortimer e Scott (2002), ao discutirem conhecimentos científicos, os professores interagem com seus estudantes de distintas maneiras que estão estruturalmente relacionadas ao modo como eles entendem e expressam suas próprias ideias. Estas, de alguma maneira, influenciarão no processo de significação vivenciado 
por eles, sendo o professor corresponsável pelo processo de conceituação em sala de aula.

Dessa forma, ressaltamos a importância de que professores possam trabalhar com perfis conceituais em sala de aula, não apenas identificando zonas de perfis em seus estudantes, mas tomando consciência de suas próprias concepções e como elas interferem na aprendizagem dos estudantes. Vygostky (1987) considera que a tomada de consciência é um ponto alto de domínio e generalização dos conceitos. Neste artigo, pretendemos verificar inicialmente se os professores percebem diferentes concepções que podem povoar o seu discurso em sala de aula, sendo este um estágio anterior ao processo de tomada de consciência.

Segundo Tavares (2008), o professor, utilizando-se do perfil conceitual, consegue identificar dificuldades dos estudantes nas discussões em sala de aula como também consegue fazer avaliações acerca do processo de ensino-aprendizagem. $\mathrm{O}$ autor ainda afirma que os perfis de concepções se tornam necessários à medida que é utilizado como recurso na compreensão das concepções prévias dos sujeitos no processo de ensino e aprendizagem e para argumentar que estas podem coexistir com os conceitos científicos. De acordo com Ribeiro (2002), o perfil conceitual é uma ferramenta de grande valia no ensino de química e de ciências, pois por meio dele, professores e estudantes conseguem realizar conexões acerca de variados estudos da química e da evolução de conceitos. O trabalho com o perfil conceitual demandará do professor uma reflexão sobre aspectos epistemológicos relacionados com os conceitos e conteúdos químicos ensinados em sala de aula. Esse é um desafio para a formação e ação docente.

\section{Metodologia}

Esta pesquisa apresenta um caráter qualitativo, interpretativo e descritivo. Segundo Severino (2007), a pesquisa qualitativa se refere a um conjunto de metodologias que caracteriza uma forma de investigação fundada em reflexões de cunho subjetivo, autônomo, mas que prima pelo rigor e qualidade do trabalho científico.

A pesquisa foi desenvolvida em duas escolas estaduais da cidade de Serra Talhada (PE), sendo uma de referência do ensino médio (Escola A) e outra de ensino regular (Escola B). A escolha destas foi feita a partir da disponibilidade dos professores em participar da pesquisa. Os sujeitos foram dois docentes da rede pública estadual da cidade que ministram aulas de química em cada uma delas. Denominamos Professor A1 aquele que atuava na Escola A, e Professor B1 o que atuava na escola B. Ao aceitarem participar da pesquisa, estes assinaram um termo de compromisso permitindo a divulgação dos dados da pesquisa.

É importante destacar que os professores participantes não têm formação específica ou licenciatura em química, contudo, lecionam essa disciplina há alguns anos e esse tempo foi considerado na escolha. Esse fato nos remete à situação crítica do déficit de professores com formação específica em química na região, o que também ocorre em outras regiões do país. Para a escolha dos sujeitos desta pesquisa, levamos em consideração que eles tivessem uma formação na grande área das ciências da natureza, considerando as afinidades das disciplinas dessa área com a química.

\section{Etapas da investigação}

A pesquisa foi realizada em três etapas: aplicação de um questionário, observação de aulas e realização de entrevista semiestruturada. A primeira etapa teve como objetivo levantar o perfil profissional de cada professor participante. Na segunda, tivemos como foco verificar as interações discursivas produzidas por eles quando ensinam o conceito de calor, identificando assim as zonas do perfil conceitual de calor (Amaral; Mortimer, 2001). Na terceira etapa, tivemos como objetivo verificar se estes tinham percepção dos diversos modos de pensar o conceito de calor que foram identificados no seu discurso.

Para coletar os dados, utilizamos equipamentos de registro de áudio e vídeo. A entrevista foi gravada em áudio com o auxílio de um gravador MP3, enquanto que as aulas foram registradas em vídeo. Também foram feitas anotações de campo que auxiliaram na organização e no tratamento dos dados. Dados obtidos dos registros em áudio e vídeo foram transcritos para a análise. O questionário aplicado aos professores no início da pesquisa foi elaborado com as seguintes perguntas:

1. Há quantos anos o senhor leciona? Não precisa considerar apenas o período em que trabalha na rede estadual, pode contar com suas experiências em redes municipais, privadas, ONGs ou federais de ensino.

2. Qual sua formação acadêmica?

3. Em quais áreas o senhor atua?

4. Há quantos anos o senhor ensina a disciplina de química?

5. Quando o senhor iniciou lecionar química, enfrentou muitas dificuldades? De quais tipos?

6. O senhor tem acesso a pesquisas na área de ensino de química? Se sim, quando iniciou esse processo de estudo? Caso não, quais os motivos o impedem de acessar?

Na segunda etapa, foi observada uma aula de 50 minutos, ministrada por eles sobre o conceito de calor e suas aplicações na química. Nessa etapa, buscamos mapear zonas do perfil conceitual de calor que emergiram nas suas falas.

Após uma semana das observações das aulas, cada um dos professores foi procurado para realizarmos uma entrevista semiestruturada. Cada entrevista teve duração de cerca de 25 minutos e foi estruturada com base na discussão feita por Viggiano e Matos (2007), sendo uma adaptação da metodologia usada por Silva (2011). Foram apresentadas a eles três situações que envolviam a compreensão do conceito de calor. Optamos por elaborar perguntas a partir de situações que os envolvessem em um contexto de aplicação do conceito de calor, 
possibilitando que se posicionassem a partir de conhecimentos sobre esse conceito.

Essa etapa foi importante porque nos possibilitou avaliar a percepção que os professores apresentavam sobre concepções representativas das zonas do perfil conceitual de calor. Na entrevista, eles poderiam expressar suas ideias sem estar envolvido com as demandas dos estudantes que, muitas vezes, orientam o discurso do professor. Dessa maneira, a partir das situações, eles puderam expressar suas ideias sobre calor, e avaliamos se havia percepção de que diferentes modos de pensar poderiam emergir nas suas falas. A nossa expectativa era de que eles apresentassem ideias que se aproximam da visão científica do conceito, já que naquele momento não estavam comprometidos com o processo de mediação para a aprendizagem de conceitos científicos pelos estudantes. A percepção dos professores com relação às zonas do perfil seria evidenciada se estes identificassem diferentes concepções e buscassem associá-las a contextos específicos de aplicação. As situações elaboradas para a entrevista são apresentadas a seguir.

$1^{\text {a }}$ situação: um jovem foi a uma loja comprar um casaco, ao chegar, dirigiu-se ao atendente e pediu "um casaco quente de lã". De acordo com a afirmação, o que ele pretendeu expressar? Qual será a função do casaco de lã? Explique esse fato.

$2^{\mathrm{a}}$ situação: um determinado professor estava saindo da sala ao término de sua aula e notou, ao pegar na maçaneta da porta, que ela estava um pouco fria e se questionou acerca do que tinha observado. Ao empurrar a porta com a outra mão, percebeu que ela estava um pouco mais quente. O que esse professor pode concluir?

$3^{\text {a }}$ situação: uma determinada pessoa saiu com amigos para lanchar, ao chegarem ao local, pediram um refrigerante. Em seguida, um membro do grupo não gostou muito da qualidade do refrigerante e pediu gelo. Qual foi a finalidade do gelo? O que acontece quando o gelo entra em contato com o refrigerante?

\section{Análise dos dados}

Nas respostas ao questionário aplicado na primeira etapa, analisamos o perfil profissional dos professores, considerando os seguintes aspectos: tempo de experiência; formação acadêmica; áreas de atuação; dificuldades enfrentadas atuando com química no ensino médio; e acesso às pesquisas na área de ensino de química. Para a análise dos dados registrados na observação das aulas, utilizamos as zonas do perfil conceitual de calor propostas por Amaral e Mortimer (2001), buscando identificá-las nas interações discursivas estabelecidas pelos professores em sala de aula. Essas zonas podem evidenciar compromissos epistemológicos e ontológicos que cada professor apresenta na compreensão do conceito de calor.

Amaral e Mortimer (2001) propuseram um perfil conceitual para calor, identificando diferentes modos de pensar esse conceito a partir de compromissos epistemológicos e ontológicos distintos. Os autores propuseram cinco zonas para o perfil conceitual de calor - realista, animista, substancialista, empírica e racionalista - que estão relacionadas com compromissos epistemológicos discutidos por Bachelard (1996), respectivamente, realismo ingênuo, animismo, substancialismo, empirismo e racionalismo. Na zona realista, destacam-se ideias de calor associadas às sensações de quente. Em diversas situações do cotidiano, é comum as pessoas relacionarem as noções de calor à sensação térmica, fazendo a diferença entre quente e frio. Na zona animista, o calor é apresentado como uma substância viva e que dá vida. Segundo Amaral e Mortimer (2001), em um período da história da ciência, o calor foi considerado como agente responsável por conceder vida a determinados objetos. Quanto à zona substancialista, o calor é tratado como uma substância inerte, diferentemente do que foi colocado na zona animista. Para essa zona, os autores fizeram considerações sobre ideias filosóficas apresentadas por Aristóteles nas quais mencionava o fogo como uma substância e sobre períodos da história da ciência em que o calor era associado a algum tipo de fluido. Na zona empírica, são encontradas ideias em que o calor é relacionado com medidas de temperatura. Essa ideia surge historicamente após o desenvolvimento do termômetro e atualmente os estudantes apresentam dificuldades em distinguir calor e temperatura. Para a zona racionalista, são consideradas ideias de calor como uma noção racional, quando este é compreendido como uma grandeza proporcional à diferença de temperatura a partir de uma relação matemática. Nessa zona, a compreensão sobre calor está próxima da visão científica na forma como é abordada nos processos de ensino, quando o calor é definido "como uma forma de energia que se manifesta a partir do contato entre dois corpos a temperaturas diferentes" (Amaral; Mortimer, 2001, p. 15).

Para identificar zonas nas falas produzidas pelos professores, foram analisados extratos de fala de cada um, nos quais emergiram ideias representativas de zonas do perfil conceitual de calor tanto na sala de aula como na entrevista semiestruturada. As falas foram transcritas e analisadas tomando por base as zonas mostradas no Quadro 1. A transcrição das falas gravadas nas aulas foi feita a partir da escolha de trechos de fala que fossem representativos de zonas do perfil conceitual. Com relação às entrevistas, foram transcritas na íntegra as falas dos professores relacionadas com as situações colocadas.

Ao final da análise, cruzamos os dados analisados, buscando estabelecer relações entre a formação do professor (aplicação do questionário), as zonas identificadas nas falas destes em sala de aula (observação das aulas) e os posicionamentos tomados na entrevista semiestruturada.

\section{Resultados e Discussão}

A partir das respostas ao questionário, foram traçados os perfis dos professores, sujeitos da pesquisa, conforme mostrado no Quadro 2. 
Quadro 1. Zonas do perfil conceitual de calor.

\begin{tabular}{|c|l|}
\hline Zona & \multicolumn{1}{|c|}{ Características } \\
\hline Realista & Calor é associado a sensações térmicas. \\
\hline Animista & Calor é considerado uma substância viva e que dá vida a outros seres/substâncias. \\
\hline Substancialista & Calor é entendido como uma substância material. \\
\hline Empírica & Calor é relacionado a medidas de temperatura com uso do termômetro. \\
\hline Racionalista & $\begin{array}{l}\text { Calor é apresentado como uma relação matemática e compreendido como uma forma de energia que se manifesta a } \\
\text { partir do contato entre dois corpos a temperaturas diferentes. }\end{array}$ \\
\hline
\end{tabular}

Fonte: Amaral; Mortimer (2001).

Quadro 2. Respostas ao questionário e perfil profissional dos professores A1 e B1.

\begin{tabular}{|c|l|l|}
\hline \multicolumn{1}{|c|}{ Características } & \multicolumn{1}{|c|}{ A1 } & \multicolumn{1}{|c|}{ B1 } \\
\hline Experiência docente & 16 anos & 12 anos \\
\hline Tempo que leciona química & 15 anos & 5 anos \\
\hline Formação acadêmica & $\begin{array}{l}\text { Licenciatura em ciências com habilitação em } \\
\text { matemática }\end{array}$ & $\begin{array}{l}\text { Licenciatura em ciências com habilitação em } \\
\text { biologia }\end{array}$ \\
\hline Disciplinas que ensina & Química, física e matemática & Biologia e química \\
\hline Dificuldades no ensino de química & $\begin{array}{l}\text { Dificuldade no laboratório e com o conhecimento } \\
\text { específico }\end{array}$ & $\begin{array}{l}\text { Dificuldade com o livro didático e atividade } \\
\text { experimental }\end{array}$ \\
\hline Acesso a pesquisas na área de química & $\begin{array}{l}\text { Sim, pesquisas de artigos na internet, revisões } \\
\text { do ENEM. }\end{array}$ & $\begin{array}{l}\text { Sim, realiza pesquisa na internet (QNESc) e } \\
\text { usa materiais das formações. }\end{array}$ \\
\hline
\end{tabular}

Fonte: Própria.

De acordo com os dados mostrados no Quadro 2, verificamos que estes atuam no ensino de química nas escolas mesmo sem ter formação específica na área. O professor $\mathrm{A} 1$ é graduado em licenciatura em ciências, com habilitação em matemática, enquanto que B1, possuindo a mesma formação, tem habilitação em biologia. Além de ensinar química, ambos também lecionam matérias de suas respectivas áreas. O professor A1 apresenta uma experiência de 15 anos no ensino de química, sendo esta maior do que a experiência de $\mathrm{B} 1$, com 5 anos, tendo ambos mais de 10 anos de experiência no magistério. As principais dificuldades expressadas pelos dois professores no ensino de química têm relação com o domínio do conhecimento químico e a realização de atividades experimentais em laboratório. Além disso, B1 ressalta sua dificuldade em trabalhar com o livro didático de química. Por fim, ambos participam de cursos de formação continuada e buscam informações sobre o ensino de química em artigos da área. Esses perfis se refletem na fala analisada para cada professor nas suas aulas de química, no qual identificamos uma grande variedade de zonas do perfil conceitual de calor. A análise das aulas de cada professor aponta para implicações desses perfis na elaboração do discurso pelo professor em sala de aula.

\section{Mapeamento das zonas do perfil conceitual de calor nas aulas}

Na observação das aulas, verificamos que os professores A1 e B1 apresentaram concepções sobre calor que representam diferentes zonas do perfil conceitual. Os resultados serão apresentados para cada professor e faremos uma síntese da análise posteriormente.

\section{Professor A1}

A aula ministrada pelo professor A1 tinha como tema calor e suas relações com a química. Ele iniciou a aula fazendo questionamentos sobre o significado do calor com os alunos e apontando suas concepções. Ao longo da aula, o professor buscou relacionar o calor a situações diversas, tais como aspectos energéticos de reações químicas, combustão de substâncias e algumas situações do cotidiano.

$\mathrm{Na}$ fala deste, identificamos concepções representativas de três zonas do perfil conceitual de calor - realista, empírica e substancialista -, sendo a zona substancialista predominante na sua fala. Em alguns momentos, A1 apresentou ideias que não se enquadravam em nenhuma zona. No Quadro 3, apresentamos trechos de falas que ilustram a emergência dessas zonas.

No primeiro trecho de fala (1) do Quadro 3, percebemos que o professor substancializa a ideia de calor ao associá-lo à energia de reação como uma quantidade. $\mathrm{O}$ uso da palavra quantidade parece ser um indício desse compromisso epistemológico. No segundo trecho (2), podemos constatar um compromisso realista pela associação da noção de calor com as sensações térmicas. Nesse caso, o professor usa a ideia de sensação para a compreensão de um fenômeno - a queima da madeira em um ambiente com ar-condicionado. Ao mencionar um valor para a temperatura 
Quadro 3. Trechos da fala do professor A1 extraídos da aula sobre calor.

\begin{tabular}{|c|l|c|}
\hline & \multicolumn{1}{|c|}{ Exemplos das falas } & $\begin{array}{c}\text { Identificação da } \\
\text { zona }\end{array}$ \\
\hline $\mathbf{1}$ & Então a energia necessária para reação ocorrer pode ser entendida como uma quantidade de calor. & Substancialista \\
\hline $\mathbf{2}$ & $\begin{array}{l}\text { Por exemplo, uma queima de madeira num sistema que tem ar-condicionado, a temperatura vai ser menor, } \\
\text { e a própria sensação térmica e a temperatura do meio está em torno de } 18{ }^{\circ} \mathrm{C} .\end{array}$ & Realista/Empírica \\
\hline $\mathbf{3}$ & $\begin{array}{l}\text { Já se fosse numa quadra (ambiente aberto), a temperatura era em torno de } 40^{\circ} \mathrm{C} \text {. Então o aumento da } \\
\text { temperatura favorece o aumento da energia das colisões. }\end{array}$ & Empírica \\
\hline
\end{tabular}

Fonte: Própria.

para o meio, A1 parece também considerar a temperatura como uma medida desse calor, apresentando ideias da zona empírica. Ao associar o calor com as sensações térmicas, sem fazer uma distinção de significados atribuídos em contextos diferentes, o professor pode contribuir para que o estudante tenha a compreensão de que o calor está relacionado apenas com o quente, reforçando uma concepção informal usada comumente no cotidiano. Alternativamente, por exemplo, poderia ser afirmado para os alunos que a concepção de calor apenas como quente não é adequada em uma visão química para o conceito, uma vez que podemos nos referir a processos de transferência de calor para corpos com baixa temperatura (frios).

No trecho de fala 3, o professor A1 associa o conceito de calor com a medida de temperatura, caracterizando uma concepção associada a um compromisso epistemológico empírico, representado pela zona empírica do perfil conceitual. Ao afirmar que "a temperatura era em torno de $40{ }^{\circ} \mathrm{C}$ ", a concepção está relacionada com valores que podem ser medidos por instrumento, ou seja, a compreensão está associada a um referente empírico. Esses trechos de fala são representativos do discurso do professor ao longo da aula observada. Verificamos que A1 não incluiu na sua fala ideias representativas da zona racionalista do perfil, o que caracteriza a ausência de uma discussão em sala de aula com base em uma visão científica do conceito. Verificamos que ele demonstrou grande esforço em relacionar o conteúdo ensinado com o cotidiano dos estudantes e, para isso, apresentou o conceito a partir de ideias que constituem zonas não científicas do perfil (realista e substancialista), aproximando-se de um modo de pensar científico pela discussão de ideias da zona empírica, mas sem aprofundar a compreensão sobre as relações entre calor e temperatura.

Um aspecto a ser considerado diz respeito ao maior ou menor domínio que o professor apresenta sobre aspectos epistemológicos e pedagógicos do conteúdo a ser ensinado. Os dados sugerem que o professor não parece consciente de que diferentes concepções sobre calor emergem na sua fala. Ao mobilizar de forma indiscriminada concepções associadas a várias zonas do perfil, este não promoveu uma discussão sobre os diferentes modos de pensar sobre o conceito, buscando relacioná-los com possíveis contextos de aplicação. Por exemplo, se ele tivesse conhecimento sobre aspectos históricos do desenvolvimento do conceito, nos quais o calor deixa de ser considerado como substância e passa a ter estatuto de energia, seria mais fácil trabalhar com as visões substancialistas de calor que ainda persistem no discurso da sala de aula.

Da mesma forma, se o professor tivesse conhecimento sobre concepções informais de estudantes sobre calor, entre outras, aquela em que eles não diferenciam o conceito de calor da ideia de sensação térmica (frio e quente), este também poderia ser um tema discutido na aula. Acreditamos que a emergência de diferentes modos de pensar o conceito na fala do professor, sem que seja feita uma discussão, pode implicar em problemas na aprendizagem dos estudantes, como o reforço de concepções informais, como apontam Silva e Amaral (2006; 2013). Esse resultado mostra indícios de que o professor $\mathrm{A} 1$ talvez não tenha consciência sobre a polissemia do conceito de calor.

\section{Professor B1}

A aula ministrada pelo professor B1 também teve como tema calor e suas relações com a química. No início da aula, o docente expôs situações contextualizadas sobre calor, ao mesmo tempo em que fazia perguntas aos alunos sobre que ideias eles tinham sobre o tema discutido. Durante o desenvolvimento da aula, B1 apresentou algumas definições dos conceitos de calor na química e na física e, em seguida, mostrou exemplos que ilustravam mudanças de temperaturas de corpos. Além disso, fez associações do calor com o sistema biológico humano, usando exemplos do cotidiano, e apontou para a absorção e liberação de energia nas reações químicas.

$\mathrm{Na}$ aula do professor B1, conseguimos identificar concepções associadas a quatro zonas do perfil conceitual de calor, a saber: realista, empírica, substancialista e racionalista. No Quadro 4, apresentamos trechos da sua fala que ilustram as zonas identificadas.

Ideias representativas da zona racionalista aparecem na fala do professor como mostrado no trecho de fala 1 do Quadro 4. O professor B1 explicita a compreensão de que calor é um processo de transferência de energia, faz uma diferenciação entre concepções da física e da química e menciona que esse conceito está relacionado com a temperatura, mostrando um compromisso epistemológico racionalista como afirmado por Amaral e Mortimer (2001).

No trecho de fala 2, aparecem ideias representativas das zonas realista e empírica, quando são mencionadas as sensações 
Quadro 4. Trechos da fala do Professor B1 extraídos da aula sobre calor.

\begin{tabular}{|c|c|c|}
\hline & Exemplos das falas & Zona \\
\hline 1 & $\begin{array}{l}\text { Existem vários conceitos de calor, a química tem um, a física tem outro, mas está relacionado à temperatura } \\
\text { e à transferência de energia. }\end{array}$ & Racionalista \\
\hline 3 & $\begin{array}{l}\text { Alguém já ouviu principalmente o povo mais velho falando: não tome banho em água quente ou morna e saia } \\
\text { na porta, ocorrerá uma mudança de temperatura. Mas não é que vai causar um mal e vai matar a pessoa, } \\
\text { mas isso vai variar de pessoa para pessoa, pois ninguém sabe como está a temperatura internamente, pois } \\
\text { na verdade a temperatura do corpo humano é de } 36,5^{\circ} \mathrm{C} \text {. }\end{array}$ & Empírica \\
\hline 4 & $\begin{array}{l}\text { Por exemplo, se seu corpo estava quente, então seu corpo vai absorver, é uma transferência de energia, } \\
\text { então até que se estabeleça um equilíbrio, é o tempo que você pode voltar. Você num pode tomar banho } \\
\text { e logo chegar a ir. Você pode não ter nada, mas pode acontecer ou ter alguma alteração interna, como } \\
\text { temperatura, dor de cabeça, entre outros. }\end{array}$ & Substancialista \\
\hline
\end{tabular}

Fonte: Própria.

de quente e frio ao mesmo tempo em que se faz referência à temperatura como se fosse uma medida do calor. No caso da zona realista, B1 associa o calor às sensações térmicas sem fazer a diferenciação de como essa compreensão se aplica em diferentes contextos. Por exemplo, ajudaria o estudante entender a transferência de energia que ocorre entre corpos quentes e frios, mas poderia ser esclarecido que o calor, na visão científica, não pode ser associado exclusivamente a corpos quentes. É relevante ressaltar que, muitas vezes, o frio é entendido como uma entidade oposta ao calor (Amaral; Mortimer, 2001). No cotidiano, comumente usamos esse modo de pensar e o frio parece ganhar estatuto semelhante ao calor, enquanto que no contexto de ensino da química, não há definição ou conceituação para o frio. Com relação à zona empírica do perfil, as ideias sobre calor estão relacionadas com a temperatura, esta compreendida como algo diferente do calor, sendo uma forma de medição da agitação das partículas nos corpos. Inicialmente, o professor B1 fez menção à temperatura como um indicador de mudanças nas sensações no contato com ambientes ou objetos e depois tratou a temperatura como se fosse o próprio calor ("noção de temperatura"). Essa fala aponta para o fato de que as zonas não se diferenciam facilmente na fala do professor. No trecho de fala 3, B1 ratifica a concepção de temperatura como medida de calor, ainda que não tenhamos evidências sobre a concepção de calor que prevalece na sua fala. Ressaltamos aqui que a discussão parece associada a um conhecimento popular sobre a conduta não recomendada de se expor a ambientes abertos após tomar um banho quente ou morno, promovendo uma mudança brusca de temperatura.

No trecho de fala 4, o professor parece materializar a noção de energia e calor ao considerar que o corpo pode absorver a energia ou calor transferido, apresentando ideias que representam a zona substancialista do perfil. A ideia de transferência associada a um processo de absorção sugere certa materialidade ao que está em movimento, principalmente pelo fato de que a situação que vinha sendo discutida desde a fala anterior parece se referir a possíveis ventos ou massas de ar frio ao qual uma pessoa se submete em ambientes abertos. A concepção de calor como substância tem origem no desenvolvimento histórico do conceito e comumente emerge em situações de ensino e aprendizagem e em contextos de aplicação desse conceito (Araújo; Mortimer, 2013).

Fazendo uma síntese da análise das aulas dos dois professores, podemos constatar que ideias representativas de diferentes zonas do perfil conceitual de calor emergiram ao longo das duas aulas, sem que eles demonstrassem uma preocupação em explicitar os diversos sentidos e significados implicados em cada uma dessas zonas. Parece-nos que, ao propor situações nas quais o conceito de calor poderia ser aplicado, estes tinham como objetivo facilitar a construção do conceito por parte dos estudantes, relacionando-o com fenômenos que eles conhecem do dia a dia, tais como as sensações térmicas ou medidas de temperatura.

No entanto, a inclusão de diferentes modos de pensar de forma indiscriminada na discussão da sala de aula, sem abordar aspectos da polissemia do conceito e dos contextos nos quais algumas concepções adquirem sentido, pode contribuir para reforçar concepções informais dos estudantes, prejudicando uma diferenciação entre modos de pensar nos contextos cotidiano e escolar e dificultando a aprendizagem de conceitos químicos (Silva; Amaral, 2006). Nesse sentido, apontamos para a importância de que o professor seja conscientizado sobre a heterogeneidade das ideias na sala de aula e a necessidade de que tais ideias façam parte da discussão em sala de aula.

Ao tomar consciência das diferentes concepções que povoam o discurso de estudantes na sala de aula, o professor poderá refletir sobre as suas próprias concepções e sobre aspectos epistemológicos, históricos e contextuais implicados no ensino de conceitos científicos. Os dados das entrevistas feitas com os professores trazem uma análise sobre o nível de percepção que estes apresentam com relação a suas concepções. 


\section{Análise da entrevista com os professores}

A entrevista com A1 e B1 teve como objetivo analisar uma possível tomada de consciência destes com relação a zonas do perfil conceitual de calor. Para isso, foram propostas três situações nas quais o conceito de calor pode ser aplicado para responder a questões colocadas. Os posicionamentos tomados pelos professores em alguns momentos não nos mostram uma emergência clara de zonas do perfil, porém percebemos modos de pensar que podem ser relacionados com as zonas. Além disso, as suas falas refletem aspectos relativos ao maior ou menor domínio que têm sobre o conceito e suas aplicações em situações distintas.

\section{Entrevista com o professor Al}

A entrevista com o professor A1 teve duração de 25 minutos. Cada uma das três situações foi colocada para o professor, sendo solicitado o seu posicionamento e a resposta à questão feita, conforme apresentado anteriormente. A entrevista foi gravada e o posicionamento do professor A1 é mostrado no Quadro 5.

$\mathrm{Na}$ análise dos posicionamentos do professor A1, podemos verificar certa confusão na utilização do conceito de calor para explicar as situações colocadas, sendo constatados indícios de algumas zonas do perfil. Isso parece ter relação com o fato de não termos identificados ideias representativas da zona racionalista na observação da aula, quando A1 apresentou predominantemente zonas do perfil associadas a modos de pensar do senso comum.

A partir do Quadro 5, podemos verificar que, na $1^{a}$ situação, o professor A1 usa modos de pensar do senso comum para explicar a função do casaco de lã, quando se refere à mudança de sensação térmica que o casaco pode promover, sem preocupações em elaborar uma explicação para essa situação em termos científicos. Isso caracteriza concepções mais intuitivas, provenientes da zona realista do perfil conceitual de calor.

Para a $2^{\mathrm{a}}$ situação, o professor demonstra um bom conhecimento na aplicação do conceito de calor para explicar a diferença da sensação térmica da maçaneta e da porta. Ele tem consciência da diferença na condutibilidade térmica, mas não menciona o conceito de calor específico na sua fala. Percebemos indícios de um entendimento racionalista da situação quando são mencionados os diferentes comportamentos dos materiais nos processos de troca de calor, sentido a partir das sensações térmicas (frio e quente). Também é considerado o fato de que a temperatura ambiente é a mesma para os dois materiais. É curioso notar que esse nível de explicação não emergiu nas falas do professor em sala de aula.

$\mathrm{Na} 3^{\mathrm{a}}$ situação, novamente verificamos um posicionamento de A1 que se orienta para a zona racionalista do perfil, visto que este demonstra ter noção da direção do fluxo de energia - do corpo mais quente para o corpo mais frio. Mesmo não usando definições formais ou explicações para o processo de transferência de calor, consideramos que, em sua resposta, há

Quadro 5. Posicionamento do Professor A1 sobre as situações da entrevista.

\begin{tabular}{|c|c|c|}
\hline $\begin{array}{l}\text { Situações } \\
\text { propostas }\end{array}$ & Respostas dos professores & Indicação de zonas \\
\hline $1^{\text {a }}$ situação & $\begin{array}{l}\text { Na verdade, ele quis expressar que ele queria um casaco feito de um material que, no caso, } \\
\text { aquecesse no período frio. É por isso que ele considerou quente. Então ele queria expressar } \\
\text { que queria que o deixasse aquecido no frio. } \\
\text { Respondendo à questão: A função do casaco de lã de deixá-lo aquecido. }\end{array}$ & Realista \\
\hline $2^{\mathrm{a}}$ situação & $\begin{array}{l}\text { Na verdade, a maçaneta, como ela é de metal, os metais são bons condutores térmicos, } \\
\text { então dá para se perceber quando se toca num metal, e a maçaneta é metálica, você } \\
\text { percebe a diferença e a variação (diferença) de temperatura entre a maçaneta e a porta. } \\
\text { Então, o metal, ele facilmente perde calor e facilmente absorve calor. Assim devido serem } \\
\text { materiais diferentes, um é de material de ferro e metálico e a porta não. } \\
\text { Respondendo à questão: Então eu consigo ver essa diferença de temperatura, agora, às } \\
\text { vezes, é a mesma temperatura do ambiente, mas é porque alguém está perdendo mais calor } \\
\text { ou absorvendo mais. }\end{array}$ & Racionalista \\
\hline $3^{\mathrm{a}}$ situação & $\begin{array}{l}\text { Na verdade, a finalidade do gelo foi diminuir a temperatura do refrigerante, se ele estava quente, } \\
\text { ele queria diminuir a temperatura dele, por isso, utilizou o gelo. Então a finalidade foi diminuir } \\
\text { a temperatura. } \\
\text { Respondendo às questões: Quando o gelo entra em contato com o refrigerante, ele diminui a } \\
\text { temperatura do refrigerante, se o refrigerante está um pouco mais quente. Vai haver uma troca } \\
\text { de calor, aí o gelo vai ganhar e o refrigerante perder calor. Então o refrigerante perde calor, já o } \\
\text { gelo está numa temperatura menor e o gelo ganha calor do refrigerante, já que ele está numa } \\
\text { temperatura maior. Assim neste sistema, vai haver uma troca de calor e depois de um certo } \\
\text { tempo, eles vão estar em equilíbrio térmico, o gelo e o refrigerante. }\end{array}$ & $\begin{array}{c}\text { Substancialista/ } \\
\text { Racionalista }\end{array}$ \\
\hline
\end{tabular}

Fonte: Própria. 
um compromisso epistemológico racionalista. Contudo, quando menciona que o "o gelo vai ganhar e o refrigerante perder calor", A1 parece estar considerando o calor como algo material, o que nos leva a considerar indícios de um compromisso também substancialista na sua fala.

O predomínio do modo de pensar realista diante da primeira situação sugere a persistência de concepções do senso comum (Mortimer, 1996) sobre o conceito de calor na fala do professor. Consideramos que ao expressar essa concepção em um contexto no qual havia uma solicitação de explicação científica, o professor parece não estar ciente sobre diferentes modos de pensar sobre calor associados a contextos de aplicação específicos. Esse fato pode ser associado também a lacunas na formação inicial, uma vez que o professor A1 tem habilitação em outra área disciplinar. Por outro lado, a expressão de modos de pensar científicos, indicados pela emergência da zona racionalista nas $2^{\mathrm{a}}$ e $3^{\mathrm{a}}$ situações, aponta para uma mudança no posicionamento do professor. Para essas situações, ele apresentou ideias que estão alinhadas com a visão científica do conceito ainda que estivesse analisando fenômenos presentes no senso comum. Várias razões podem ser cogitadas para essa mudança no posicionamento do professor, entre as quais, destacamos: familiaridade com as situações, maior comprometimento com as respostas, melhor compreensão da questão e outros.

\section{Entrevista com o professor B1}

A entrevista com o professor B1 foi realizada nos mesmos moldes daquela já descrita para A1 com tempo de duração aproximadamente igual. B1 expressou ideias representativas de duas zonas do perfil conceitual de calor para explicar as situações: substancialista e a realista. No Quadro 06, ilustramos os dados com as zonas identificadas.

Da mesma forma como foi observado para o professor A1, algumas zonas não ficaram claras na fala de B1, mas percebemos alguns indícios de zonas principalmente com ideias não científicas. Diferentemente do que aconteceu na sala de aula quando a zona racionalista emergiu em alguns momentos, este não utilizou ideias racionalistas para responder às questões propostas nas situações. Na primeira situação, ele expressou ideias intuitivas, comumente usadas no senso comum, evidenciando a função do casaco em promover a sensação térmica quente. Da mesma forma como ocorreu para A1, esse modo de pensar se refere a uma zona realista do perfil conceitual.

Na segunda situação, o professor B1 mais uma vez apresenta ideias representativas da zona realista, quando sugere de forma confusa que as temperaturas são diferentes devido às diferenças nas sensações térmicas sentidas na maçaneta e na porta. Ele usa a noção de transferência de calor entre os materiais e o corpo, buscando explicar as diferentes sensações, mas as afirmações não parecem conclusivas e sugere haver uma tendência de tratar o calor transferido como algo material. Como para A1, não há menção ao conceito de calor específico e, no caso de B1, também não é feita referência à condutibilidade térmica dos materiais.

Na terceira situação, o professor B1 apresenta erros conceituais em sua resposta. Ele demonstra não saber o sentido da transferência de calor ("no caso do refrigerante para o gelo, ou do gelo para o refrigerante") e faz menção à absorção de temperatura, mostrando uma compreensão confusa dos

Quadro 6. Posicionamento do professor B1 sobre as situações da entrevista.

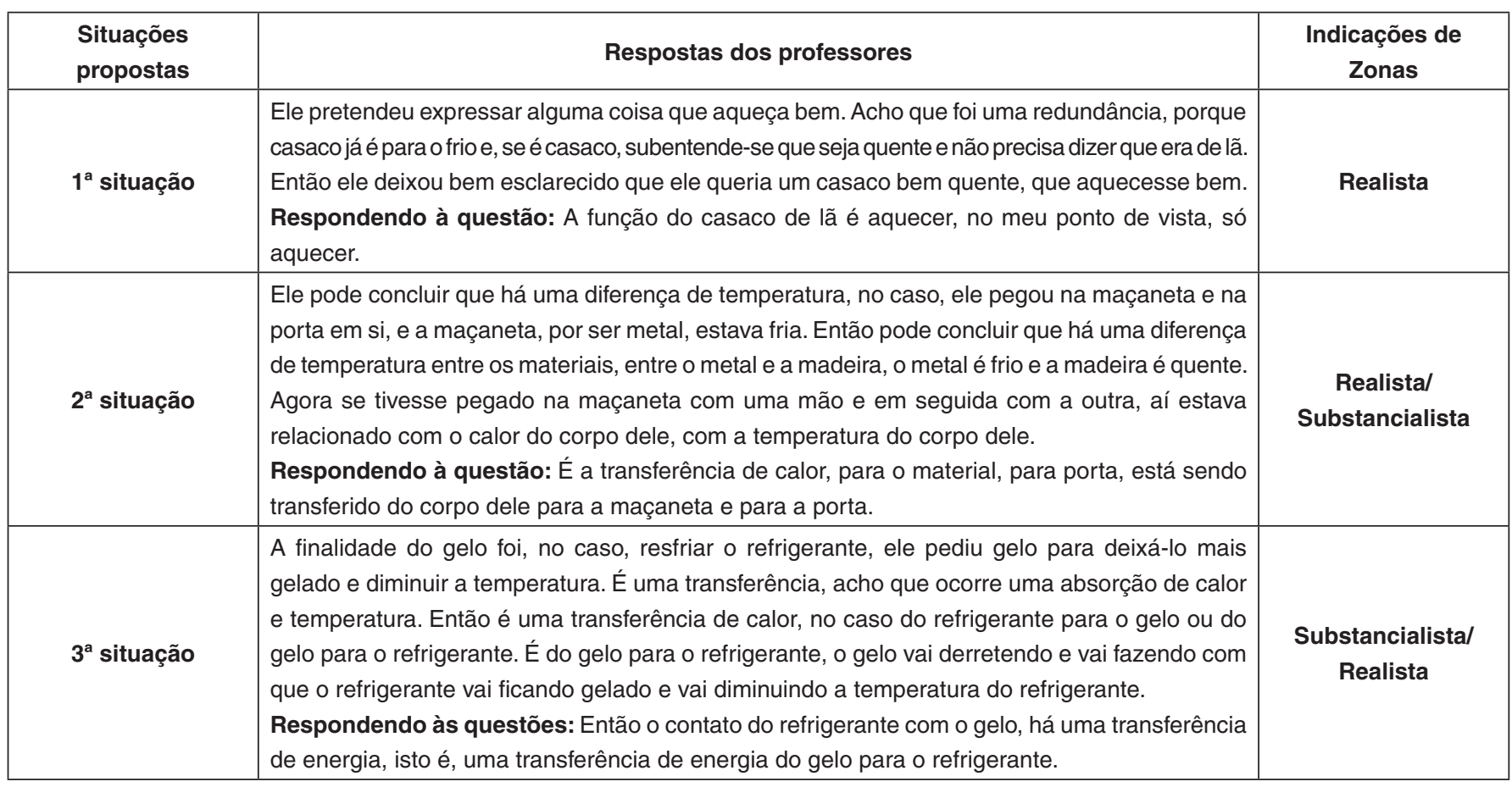

Fonte: Própria. 
conceitos de calor e temperatura. No final, ele conclui que a energia é transferida de um corpo frio (gelo) para um corpo quente (refrigerante), o sentido inverso ao que se estabelece em termos científicos. Parece-nos que foi feita uma tentativa de usar ideias científicas para elaborar uma explicação, sem que houvesse domínio sobre os significados dos conceitos envolvidos. O professor se refere a dois processos - o derretimento do gelo e o resfriamento do refrigerante -, considerando que, ao derreter, o gelo transfere calor para o refrigerante, diminuindo sua temperatura. Nesse sentido, o calor seria compreendido como algo que se transfere por meio de um material (zona substancialista) e o que orienta o fluxo de calor é uma ideia intuitiva vinculada às sensações - o "frio" do gelo se transfere para o refrigerante (zona realista).

Nas entrevistas dos dois professores, podemos identificar ideias representativas de diferentes zonas do perfil conceitual de calor, ideias que nem sempre são claras ou facilmente compreendidas. Isso evidencia o pressuposto da teoria do perfil conceitual quando aponta para a coexistência de outros modos de pensar com as ideias científicas. Esses modos de pensar emergem na discussão de sala de aula e, muitas vezes, não são percebidos por professores e estudantes, o que nos aponta para a necessidade de reflexão sobre a polissemia dos conceitos e sobre a relação entre modos de pensar e contextos.

De uma forma geral, a análise dos dados mostra que os professores não têm percepção sobre os diversos modos de pensar o conceito de calor que povoam as suas falas em sala de aula. Dessa forma, eles também não se apropriam das diferentes epistemologias que podem estar implicadas nas ideias discutidas na sala de aula e não identificam a multiplicidade de sentidos que os conceitos podem adquirir em contextos diversos.

\section{Perfil profissional e zonas do perfil}

Após a discussão apresentada anteriormente, buscamos contrastar dados de forma a identificar possíveis relações entre aspectos do perfil profissional do professor e a limitada percepção sobre a relação entre modos de pensar e contextos de aplicação. Partimos da constatação de que existe uma heterogeneidade de modos de pensar explícitos nas falas destes quando expõem e discutem o conteúdo a ser ensinado na aula. Para A1, identificamos as mesmas zonas tanto nas interações discursivas da sala de aula quanto na entrevista, com exceção da zona racionalista que emergiu apenas na entrevista. No caso do B1, foram identificadas várias zonas em suas falas na sala de aula, enquanto que na entrevista a emergência de zonas foi mais restrita. Nos dois casos, acreditamos que a diversidade de zonas que emergiram na aula fazia parte de um repertório de ideias organizadas para a apresentação do conteúdo em um formato compreensível para os estudantes. Com isso, na aula, muitas vezes, os professores buscaram utilizar uma linguagem mais simples, ficando restrito à discussão de concepções representativas de zonas não científicas.
As ideias que emergiram nas entrevistas parecem mais relacionadas com o domínio do conteúdo específico e com a formação inicial. Observamos que, quando o professor é colocado diante de situações para as quais deve elaborar uma explicação, há uma necessidade de que sejam mobilizadas ideias que ajudem a resolver o problema. Por isso, pudemos identificar tentativas de explicar as situações com visões científicas, ainda que não houvesse uma completa sistematização dos conceitos. Uma exceção a isso ocorreu na primeira situação, quando foram identificadas visões ingênuas para a explicação dos fenômenos, o que se enquadra na zona realista do perfil. Ao utilizarem zonas não científicas para resolver situações, podemos inferir que eles não apresentam uma reflexão ou percepção sobre a pertinência de suas próprias concepções.

Aspectos do perfil dos professores podem contribuir na busca de razões pelas quais os professores não estão atentos às suas próprias concepções. Com relação à experiência docente e formação inicial, verificamos para ambos que a tentativa de mobilização de ideias relativas à zona racionalista, evidenciada mais na entrevista do que na sala de aula, pode ser reflexo do tempo de experiência no ensino de química. De acordo com o Quadro 2, o professor A1 ensina química há 15 anos e B1, há 5 anos. Acreditamos que a maior experiência docente de A1 fez com que este mobilizasse ideias mais voltadas à visão científica do conceito de calor na entrevista. Contudo, os anos de experiência não parecem suficientes para suprir lacunas sobre o conteúdo de química, provavelmente oriundas de uma formação inicial com habilitação em matemática. Dessa forma, na sala de aula e na entrevista, também emergem na fala de A1 zonas realista, substancialista e empírica, sendo essa última a única que se aproxima da visão científica do conceito de calor.

O professor B1 expressou ideias representativas da zona racionalista em alguns momentos da aula, mas apresentou ideias confusas durante a entrevista. Podemos levantar a possibilidade que o professor tenha um planejamento de aula a partir de consulta a livros didáticos e outros textos, o que orienta sua maneira de falar. Na entrevista, o professor não contou com o mesmo suporte, posicionando-se a partir dos conhecimentos consolidados em 5 anos de experiência de ensino de química, uma vez que a sua formação inicial foi na área de biologia. Isso poderia explicar a presença de erros conceituais e falta de sistematização de ideias.

A ausência de uma exposição sistematizada do conceito, a incidência de erros conceituais e o uso de ideias de senso comum para explicar situações ou fenômenos em um contexto científico também podem emergir na fala de professores com formação em química. De uma forma geral, professores e estudantes, muitas vezes, encontram dificuldades em compreender aspectos mais complexos do conceito de calor, alguns deles abordados em livros didáticos do ensino médio. $\mathrm{Na}$ formação inicial de professores de química, os estudantes encontram condições de estudos e de discussão sobre esse conceito, possibilitando uma melhor apropriação dos seus 
significados e aplicação. No entanto, mesmo professores com formação específica em química podem apresentar diferentes modos de pensar e falar sobre o calor. Com isso, estamos certos de que a formação inicial em química tem papel crucial no desempenho de professores em aulas de química, mas essa formação não exclui a necessidade de reflexão sobre aspectos epistemológicos, históricos e contextuais relacionados com os conceitos químicos. Dessa forma, nossos resultados ratificam a necessidade de que sejam introduzidas discussões sobre a epistemologia da ciência na formação inicial de professores (Cachapuz et al., 2011; Junqueira; Maximiano, 2011), a partir das quais poderá ser compreendida a natureza do conhecimento científico e as suas relações com outras formas de conhecimento, principalmente o senso comum.

\section{Considerações Finais}

Este artigo teve como objetivo identificar zonas do perfil conceitual de calor que emergem nas falas de dois professores de química em duas escolas públicas de Pernambuco. Além disso, analisamos se os professores tinham percepção das concepções expressadas nas discussões em sala de aula. A partir da análise, verificamos que estes expressam ideias representativas de diferentes zonas do perfil e que eles parecem não ter percepção sobre as suas próprias concepções. Aspectos como formação inicial e experiência docente podem estar relacionados com a emergência de algumas zonas do perfil conceitual de calor. Os resultados encontrados apontam para a necessidade de uma formação epistemológica para professores, o que pode ser viabilizado a partir da inserção de estudos sobre o perfil conceitual (Mortimer, 1995; Mortimer; El-Hani, 2014) em cursos de formação inicial e continuada de professores de ciências.

Consideramos que a inserção de estudos sobre perfis conceituais em cursos de formação de professores pode contribuir para uma visão mais ampla dos conceitos científicos, levando-os a inovar o discurso produzido em suas aulas. Essa inovação inclui a apresentação de aspectos do desenvolvimento histórico dos conceitos, dos diferentes significados que estes podem adquirir em contextos diversos, promovendo contextualização sociocultural nas suas aulas. A necessidade de contextualização dos conteúdos escolares, a partir da aproximação de conhecimento científico historicamente situado, conhecimento cotidiano e outras formas de conhecimento, pode representar um desafio para o professor.

A compreensão ou explicitação de relações entre modos de pensar e os contextos nos quais eles podem ser aplicados pode contribuir para uma ampla e significativa aprendizagem dos conceitos científicos, considerando o sentido que alguns modos de pensar ganham em contextos específicos. Por exemplo, na sala de aula, pode-se problematizar a tentativa de uso de ideias do senso comum para resolver questões no contexto científico e, da mesma forma, como os conceitos científicos contribuem para explicar situações cotidianas. Nesse sentido, consideramos que a construção de relações entre diferentes modos de pensar e destes com os diversos contextos de aplicação, entre outros, pode constituir-se como uma abordagem inovadora para o ensino.

\section{Referências}

AGUIAR JR., O.G.; MORTIMER, E.F. Tomada de consciência de conflitos: análise da atividade discursiva em uma aula de ciências. Investigações em Ensino de Ciências, v. 10, ed. 2, p. 179-207, 2005.

ARAÚJO, A.O.; MORTIMER, E.F. A utilização do conceito de calor por bombeiros militares e técnicos em refrigeração de ambientes. In: ENCONTRO NACIONAL DE PESQUISA EM EDUCAÇÃO EM CIÊNCIAS, 9, 2013. Atas... Águas de Lindóia, 2013.

AMARAL, E.M.R.; MORTIMER, E.F. Uma proposta de perfil conceitual para o conceito de calor. Revista Brasileira de Pesquisa em Educação em Ciências. Belo Horizonte. v. 1 n. 3 p. 1-16. 2001.

Un perfil conceptual para entropia y espontaneidad: una caracterizacion de lãs formas de pensar y hablar en el aula de química. Educacion química, n. 3:60-75, 2004.

. Uma metodologia para análise da dinâmica entre zonas de um perfil conceitual no discurso da sala de aula. In: SANTOS, F. M. T.; GRECA, I. M. (Orgs.). A pesquisa em ensino de ciências no Brasil e suas metodologias. Unijuí: Ed. Unijuí, 2006, p. 239-296.

BACHELARD, G. A formação do espírito científico. Trad. Estela dos Santos Abreu. Rio de Janeiro: Contraponto, 1996.

BAKHTIN, M.M. The dialogic imagination: Four essays (Editor: M. Holquist, Tradução: C. Emerson e M. Holquist). University of Texas Press Slavic Series (Book 1). Austin: University of Texas Press. 480p. 1981.

Speech genres and other late essays. Austin, TX: University of Texas Press, 1986.

CACHAPUZ, A.; GIL-PEREZ, D.; CARVALHO, A.M.P.; PRAIA, J.; VILCHES, A. (Orgs.). A necessária renovação do ensino de ciências. São Paulo: Cortez, 2011.

CHAVES, T.A.; COUTINHO, F.A.; MORTIMER, E.F. A expressividade do futuro professor de química: recursos vervais e não verbais. Revista Brasileira de Ensino de Ciência e Tecnologia, v. 2, n. 1, 2009.

COBERN, W.W. Worldview theory and conceptual change in science education. Science Education, 80, 579-610, 1996.

JUNQUEIRA, M.M.; MAXIMIANO, F.A. A evolução das concepções sobre a natureza da ciência na formação inicial de professores de química. In: ENCONTRO NACIONAL DE PESQUISA EM ENSINO DE CIÊNCIAS, 5, 2011. Atas... Campinas: ABRAPEC, 2011.

MENDES, L.G.L.; SILVA, J.R.R.T. Mapeamento de zonas do perfil conceitual de substância no ensino médio. In: ENCONTRO NACIONAL DE EDUCAÇÃO, CIÊNCIA E TECNOLOGIA, 2012. João Pessoa: UEPB, 2012.

MORTIMER. E.F. Conceptual change or conceptual profile change? Science \& Education. Amsterdam: Kluwer, p. 268-283, 1995. 
Construtivismo, mudança conceitual e ensino de ciências: para onde vamos? Investigações em Ensino de Ciências. v. 1, p. 20-39, 1996.

. Para além das fronteiras da química: relações entre filosofia, psicologia e ensino de química. Química Nova, p. 200-207, 1997.

. Linguagem e formação de conceitos no ensino de ciências. Belo Horizonte: Ed. UFMG, 2000.

MORTIMER, E.F.; SCOTT, P. Atividade discursiva nas salas de aulas de ciências: uma ferramenta sociocultural para analisar e planejar o ensino. Investigações no Ensino de Ciências, Porto Alegre, v. 7, n. 3, p. 283-306, 2002.

MORTIMER, E.F.; EL-HANI, C.N (Eds). Conceptual Profiles: A theory of teaching and learning scientific concepts series. Contemporary trends and issues in Science Education. Holanda: Springer. 330p. 2014.

MORTIMER, E.F.; SCOTT, P.H.; AMARAL, E.M.R., EL-HANI, C.N. Conceptual profiles: theoretical-methodological bases of a research program. In: MORTIMER, E.F.; EL-HANI, C.N.(Eds) Conceptual Profiles: A theory of teaching and learning scientific concepts series. Contemporary trends and issues in Science Education. Holanda: Springer. 330p. 2014.

NÓBREGA, J.J.S. Possíveis relações entre gêneros de discurso e zonas do perfil conceitual em licenciandos de química da UAST. 2013. 48 f. Monografia (Graduação) - Licenciatura Plena em Química, Universidade Federal Rural de Pernambuco, Serra Talhada, 2013.

RIBEIRO, H. Construindo um perfil conceitual a partir de algumas teorias de ácido-base. 2002. 24 f. Monografia (Pós-graduação em Química) - Departamento de Química, Universidade Federal de Lavras, Lavras, 2002.

SEVERINO, A.J. Metodologia de trabalho científico. 23. ed. São Paulo: Cortez, 2007.
SILVA, J.R.R.T. Um perfil conceitual para o conceito de substância. 2011. 183 p. Dissertação (Mestrado) - Programa de Pós-Graduação em Ensino das Ciências, Universidade Federal Rural de Pernambuco, Recife, 2011.

SILVA, J.R.R.T.; AMARAL, E.M.R. Proposta de abordagem para o ensino de reações químicas a partir da noção de perfil conceitual. In: ALBUQUERQUE, U.P.; VERAS, A.S.C.; FREIRE, F.J.; LIRA JÚNIOR, M.A. (Orgs.). Caminhos da ciência. v. 1. Recife: EDUFRPE, 2006. p. 259-273.

Proposta de um perfil conceitual para substância. Revista Brasileira de Pesquisa em Educação em Ciências. v. 13, n. 3, 2013.

TAVARES, C.M. O perfil conceitual e a construção de conceitos científicos em sala de aula. 2008. 47 p. Monografia (Graduação em Licenciatura em Química) - Faculdade de Educação, Universidade Federal de Minas Gerais, Belo Horizonte, 2008.

VIGGIANO, E.; MATTOS, C.R. É possível definir contextos de uso de zonas de perfil conceitual com um questionário? In: VI ENCONTRO NACIONAL DE PESQUISA EM ENSINO DE CIÊNCIAS, Atas. Bauru: ABRAPEC, 2007.

VYGOTSKY, L.S. Mind in society: The development of higher psychological process (M. Cole, V. John-Steiner, S. Scribner \& E. Souberman, Eds.). Cambridge, MA: Harvard University Press. 159p. 1978.

The genesis of higher mental functions. In: WERTSCH, J.V. (Ed.). The concept of activity in soviet psychology. Armonk: Sharpe, 1981. p. 144-188.

VYGOTSKY, L.S. Thinking and speech. In: RIEBER, R.W.; CARTON, A.S. (Eds.). The collected works of L. S. Vygotsky: Problems of general psychology, including the volume thinking and speech. 396p. New York: Springer. 1987. 